\title{
Food Vendor Beware! On Ordinary Morality and Unhealthy Marketing
}

\section{Tjidde Tempels $s^{1,2,3} \cdot$ Vincent $^{B^{\prime}}$ lok $^{3} \cdot$ Marcel Verweij $^{3}$}

Accepted: 16 December 2019 / Published online: 26 December 2019

(C) The Author(s) 2019, corrected publication 2020

\begin{abstract}
Food and beverage firms are frequently criticised for their impact on the spread of noncommunicable diseases like obesity and diabetes type 2 . In this article we explore under what conditions the sales and marketing of unhealthy food and beverage products is irresponsible. Starting from the notion of ordinary morality we argue that firms have a duty to respect people's autonomy and adhere to the principle of non-maleficence in both market and nonmarket environments. We show how these considerations are relevant when thinking about immoral behaviour in the food and beverage industry, and identify under what conditions sales and marketing of unhealthy foods and beverages to adults and children is wrong. Based on this analysis we argue that firms should take into account: whether consumers are able to identify manipulative marketing, the degree of manipulation, as well as the negative impact a product has on health. We hold that for the food industry to act responsible it should re-evaluate the marketing of unhealthy products to adults and refrain from marketing to children. We conclude this study by making several recommendations on how the food industry should interact with consumers and highlight what changes need to be made in corporate practice.
\end{abstract}

Keywords Food industry · Manipulation · Marketing · Public health · Corporate responsibility

Tjidde Tempels

t.tempels@ reflects.ru.nl

Vincent Blok

vincent.blok@wur.nl

Marcel Verweij

marcel.verweij@wur.nl

1 Institute for Management Research, Radboud University, Post Box 9108, 6500 HK Nijmegen, The Netherlands

2 Faculty of Philosophy, Theology and Religious Studies, Post Box 9103, 6500 HK Nijmegen, The Netherlands

3 School of Social Sciences, Wageningen University, Hollandseweg 1, 6707 KN Wageningen, The Netherlands 


\section{Introduction}

In the debate on corporate responsibility there is ongoing discussion on the legitimate impact of businesses on public issues. One of the sectors where firms are increasingly attributed responsibility is in the food and beverage industry ${ }^{1}$, where firms are criticised and held responsible for the rise of non-communicable diseases (NCDs) such as cardiovascular disease and type 2 diabetes (Dorfman et al. 2012; Nestle 2018; Stuckler and Nestle 2012).

While NCDs occur as the result of a variety of behavioural, genetic and environmental factors, they are frequently associated with unhealthy diets. Dietary choices affect our health as (over)consumption of unhealthy food products ${ }^{2}$ foster metabolic risk factors like obesity and high blood pressure, which can lead to NCDs (WHO 2018). Recent empirical studies show how the consumption of unhealthy food products like soft drinks, red meat and ultra-processed foods has steadily grown over the past years (cf. Afshin et al. 2019; Imamura et al. 2015; Micha et al. 2015). These developments have led public health scholars such as Nestle (2013, 2015) and Hastings (2012) to critically evaluate the role food and beverage firms play in the spread of NCDs. They hold that the rise of these diseases is directly connected to market activities of the food and beverage industry, as the products these firms put on the market to a large extent shape and determine what our diets look like, and contribute to the creation of an obesogenic environment. Through production, marketing and involvement in science and politics these firms have become one of key factors in the global obesity epidemic (Brownell and Warner 2009; Dorfman et al. 2012; Harris et al. 2009; Nestle 2013).

Because of this impact critical public health scholars call out for a fundamental change in the industry, entailing both a change in the way products are developed and designed as well as a change in the means of marketing and product promotion. They are often pessimistic about the possibility of 'Big Food' changing their activities for the better. Rather than trusting firms' abilities for self-regulation, these critics put forth that stronger governmental regulation of the industry is a bare necessity (Marks 2017; Moss 2013; Nestle 2015). Only through laws that enable the taxation of unhealthy products, limit corporate influence on public policy making and prohibit marketing to vulnerable populations, can the negative impact on public health be curbed (Gilmore et al. 2011; Stuckler et al. 2012; Yoon and Lam 2013).

On the other side of the aisle business scholars point out that the rise of NCDs cannot be fully attributed to Big Food as the increased prevalence of these diseases is the result of the interplay of decisions and behaviours of various private and public actors. Businesses can provide healthier options and inform people about what healthy consumption and behaviour would be, but in the end it is the consumer that makes the decision to eat (un)healthy or to engage in unhealthy behaviour (cf. Epstein 2004; Iivonen 2017).

\footnotetext{
${ }^{1}$ We focus in this article on companies and firms that produce and sell food and beverage products. We use the terms food and beverage industry, food industry and beverage industry interchangeably.

${ }^{2}$ Although the idea of a clear distinction between healthy and unhealthy food and beverage products can be contested (Katan 2017), there are varieties of products that when regularly consumed (like products with relatively high amounts of sugar, salt and fat) are likely to have a negative impact on health (Afshin et al. 2019; Swinburn et al. 2011). In this article we follow the definition of Barnhill and her colleagues who refer to unhealthy food and beverage products as "foods that significantly increase the risk of diet-related illness at current levels of consumption, but do not pose a risk of immediate harm, and whose risk-attributing components are themselves food substances (e.g., fat, sugar, or salt)" (Barnhill et al. 2014, p. 192). Classic examples of these products are sugary drinks (e.g. regular Coca- Cola), certain types of fast food (e.g. KFC's chicken wings) and processed foods that are high in salt, sugar or fat (e.g. potato chips) (cf. Barnhill et al. 2014; Nestle 2013, 2015).
} 
At the same time, this does not do away with the fact that these firms have an important role in sustaining the prevalence of NCDs. It is the interplay of practices of industry in the market and society at large that create, induce and enable specific patterns of unhealthy consumption that contribute to obesity and other NCDs. While governmental action is necessary to deal with this epidemic, this does not mean we should not think about industry's responsibility and what they should and should not do to address these problems (Schrempf 2014; Tempels, Verweij and Blok 2017).

From a normative perspective it can be argued that firms in the food and beverage industry have a mediated causal connection to food-related public health problems, and because of this have a responsibility to address these controversies and should work towards addressing consumption-related NCDs. This responsibility is forward-looking, and is framed in terms of positive action: what can businesses do to turn the tide in the global obesity epidemic? And how they can strengthen healthy consumption? It provides guidance in what kind of affirmative actions would be morally desirable, e.g. businesses should develop more healthy products, encourage people to have a healthy energy balance, nudge people towards healthier decisions and maybe even encourage stricter public health regulation (Blok, Tempels, Pietersma and Jansen 2017; Schrempf 2014; Tempels, Verweij and Blok 2017).

Yet, to fully understand what corporate responsibility for public health can entail for food firms, we should not only think of the kind of positive actions corporate actors can engage in. Firms are often keen to point out what kind of activities they are willing to take up in their long-term strategies, but find it harder to point out what kind of things they will no longer do. In this article we provide a normative reflection on the moral impermissibility of several market practices in the food and beverage industry. For in order to say something about responsible corporate behaviour, we should also assess what kind of activities are morally problematic. To do this we assess what kind of behaviour in the food industry that impacts public health violates basic moral requirements, and thus are moral wrongs which firms should refrain from engaging in. In the following sections we explore under what conditions the sales and marketing of unhealthy food and beverage products is irresponsible.

In order to provide a plausible answer to this problem we first briefly set out what these basic moral requirements are. We draw from the contemporary debates on ordinary morality and corporate responsibility to highlight non-maleficence and the notion of respect for autonomy as central principles that need to be adhered to when engaging in market and non-market activities (cf. Brenkert 2008; Gert 2004; Hsieh 2017). On the basis of this we discuss how the principle of non-maleficence and the notion of respect for autonomy are relevant when thinking about immoral behaviour in the food and beverage industry. We show how health harms are not a sufficient consideration for arguing that sales and marketing of unhealthy food products would be irresponsible, and hold that respecting autonomous choice is at the heart of this debate. In the later sections we look at under what circumstances marketing to adults can be understood as wrongful and we assess the problems in marketing unhealthy food and beverages to children and teenagers. On the basis of this we find three conditions under which sales and marketing of unhealthy products is irresponsible. In the final section we reflect on what these findings imply for corporate practice and make recommendations for future research.

\section{Ordinary Morality - A Basic Minimum for Businesses}

In business ethics there is considerable discussion on what kind of moral principles should guide the behaviour of individuals and organisations. Several authors argue that there are basic 
principles of morality that regulate how we ought to behave. Gert (2004) provides such a theory. He understands morality as:

"an informal public system applying to all rational persons [...] governing behaviour that affects others, and includes what are commonly known as the moral rules, ideals, and virtues and has the lessening of evil (harm) suffered by those protected by the system as its goal." (Gert 2004, p. 156)

He argues that harm - here understood as death, pain, disability, loss of freedom and loss of pleasure - is something all rational actors try to avoid. Rational actors are to refrain from directly harming others, or engage in activities that would likely result in harms to others (deceive, break promises, cheat, break the law, not doing one's role specific duties) (Gert 2004).

While Gert specifically talks about moral behaviour in society in general, Nien-hê Hsieh (2017) makes a comparable argument when discussing what kind of principles should guide the behaviour of corporate actors. Taking a stance counter to scholars such as Joseph Heath (2007) and Wayne Norman (2011) who argue in favour of a specific (adversarial) morality for the market, Hsieh argues that ordinary morality provides a solid framework for the responsibilities of firms and their managers in relation to their consumers and society at large. In reference to this ordinary morality Hsieh points out that negative duties such as the responsibility to refrain from harming others and undermining the autonomy of other actors, are wellestablished, and should be adhered to both in the market as well as in society (cf. Lichtenberg 2010). These basic moral rules can help establish a more clear idea about what kind of activities are permissible and which are not, and provide guidance to how firms and people working in business ought to act (Hsieh 2017).

In an ideal world people and organisations would adhere to rules of ordinary morality, act upon these principles and regulate their own behaviour. Yet, there will always be unforeseen consequences of our actions and unexpected events to deal with. For that reason we need rules and regulation to provide a safety net, allowing us to not have to solely trust on the good intentions of others. We also see this in the food and beverage industry: most governments provide laws and regulations to structure the food market and for instance set safety standards for products.

At the same time not everything can be regulated by the government. In the Netherlands for example communication about healthy food is not controlled by the government, but is left to the industry. It is expected to self-regulate and contribute to public health. Yet, in the wake of the rise of NCDs and the global obesity epidemic, numerous authors argue that we cannot expect much of corporate actors when it comes to taking responsibility for public health. They put forth that more governmental rules and legislation are the only way to deal with the spread of food-related public health harms (McKee and Stuckler 2018; Nestle 2015).

While state regulation is an absolute necessity in dealing with the surge of NCDs, we hold that by only focusing on regulation, there is a risk of reducing business ethics to obeying the law. Arguably ethics is about more than just adhering to the moral minimum that is formalised in legislation. In our daily activities we are often confronted with situations that the law does not fully cover, yet we still hope actors would engage in moral behaviour - even if this is not specifically outlined in rules or legislation. Furthermore, laws might be ineffective, morally insufficient or even unethical. If we only refer to the law as the minimal moral standard, current injustices as well as new developments that might lead to harm might not be sufficiently addressed (Gert 2004). In order to act responsible, corporate actors need to 
continually reflect on this in their daily activities. So rather than only asking 'Is this product meeting the governmental safety standards?' or, 'Is this marketing tool deceptive according the new sector guidelines?' in order to speak of corporate responsibility people in business would have to reflect on the acceptability of their actions based on central principles in ordinary morality. They ought to reflect upon whether their products and actions might unduly harm others, or infringe upon autonomy in some way - even in absence of legal rules.

Following Gert and Hsieh we discern two overarching principles from ordinary morality that hold sway in thinking about what corporate practices are morally (un)acceptable, namely 1) the principle of non-maleficence (or the duty not to harm) and 2) respect for autonomy (Brenkert 2008; Brockway 1993; Crossley 1999; Gert 2004; Hsieh 2017). In the next section we will discuss these two principles and set out what this can imply in the industry's provision of unhealthy foods and beverages.

\section{Health Harms and Respect for Consumer Autonomy in the Food and Beverage Industry}

In this section we briefly set out the principles of non-maleficence and respect for autonomy, see what adhering to these principles can imply for food firms, and illustrate this by touching upon some health-related issues.

\section{Harm and Non-maleficence in the Food Industry}

One of the primary principles in ordinary morality is the principle that one ought not to inflict harm upon others (cf. Beauchamp and Childress 2009; Feinberg 1989; Gert 2004). What harm exactly consists of is up for debate, but as Beauchamp and Childress state: "although harm is a contested concept, everyone agrees that significant bodily harms and other setbacks to significant interests are paradigm instances of harm" (Beauchamp and Childress 2009, p. 152, emphasis added).

There are instances under which harm might be legitimately inflicted upon others, namely when the harm is consensual. People often engage in activities that can bring about financial or bodily harm (e.g. they go base-jumping, consume alcohol and smoke cigarettes etc.). We commonly assert that such actions do not constitute a moral wrong, as long as the harm risked or incurred was done so knowingly and willingly by the persons involved in these activities. The notion that this is morally permissible can be traced back to the ancient maxim of volenti non fit injuria ("To one who has consented no wrong is done") (Brink 2016). So, when a person consents to being harmed or is voluntarily exposed to the risk of harm - so there was no coercion, misinformation or undue influence - we cannot understand this as a moral wrong. Both this understanding of harm as well as the volenti principle have important implications for how to assess the (ir)responsibility of the food industry in selling unhealthy products.

\section{The Regulated Wrongs: Non-consensual Harms to Health and Unsafe Food}

In the context of the food market the possibility of harm is most clear in the case of unsafe foods. A company is blameworthy when it knowingly and willingly engages in sales activities that it knows can harm its consumers. We can speak of blameworthy harm when a producer intentionally makes use of ingredients that have harmful effects, or knowingly distributes 
tainted food. The latter for instance happened at the Peanut Corporation of America. In 2008 and 2009 the company was responsible for Salmonella contamination of 714 people, of which nine eventually died. The management of the firm was considered blameworthy, because it knowingly sold the infected food across the country, and actively tried to conceal the issue at hand (Leighton 2016; Marler 2018) .

In absence of clear harmful intent, firms can still be held responsible for harms that occur because of negligence. Food producing companies might be considered negligent when they unknowingly put products on the market that do not meet the required food safety standards. In these cases it is argued that even though they were unaware, they could or should have known this. For instance in 2012 the owners and operators of a melon farm had unknowingly introduced cantaloupe melons to the market that contained the harmful Listeria bacteria. The company failed to act, while there was a clear expectation that firm would care for this. As a result the owners of the farm faced up to six year in prison and a fine of 3 million dollars (Marler 2018).

In these instances food firms can clearly be held morally responsible for harms to health and appeals to the volenti principle will not do. Consumers are not in a position to discern safe from unsafe foods, and if they would have a real choice, few would voluntarily choose for unsafe food. Precisely because they are not in a position to choose for themselves, we expect the government to secure food safety. The core implications of the principle of nonmaleficence are thus governed by often strict legal regulations and inspections. Legal obligations of food companies to maintain food safety standards are therefore much more prominent than the concurrent ethical principle of non-maleficence.

\section{A less Obvious Case: Negative Health Effects of Unhealthy Food Products}

Following Barnhill et al. (2014) we make the distinction between unsafe and unhealthy food. Unsafe food in her view refers to foods that pose a risk of immediate harm (for instance food mixed with arsenic), foods that pose a risk of harm at any level of consumption (such as disease-carrying food) or products where the risk is induced through non-food substances (e.g. foods containing mercury). Unhealthy food products on the other hand are those products that significantly increase the risk of food-related health harms (such as non-communicable diseases), but do not pose an immediate harm to health, and whose risk-attributing components are food substances (e.g., salt, sugar, fat) (Barnhill et al. 2014).

Several public health professionals argue that unhealthy food products in themselves are a problem as frequent consumption negatively impacts people's health, and therefore the sales of such products should be limited or even banned (cf. Nestle 2013). The problem with such a position is that it overlooks non-health values and the importance of consumer choice. While we do not dispute that health is essential and greatly valued by most people, that does not mean it cannot be weighed against other valuable experiences. Many consumers prefer the shortterm hedonic pleasures provided by unhealthy products that are high on sugar, salt and fat, over avoiding elevated health risks later in life (Barnhill et al. 2014; Conly 2013). Unhealthy food products and eating practices bring pleasure in terms of taste and can be of social and cultural value. Now, given the possibility of consumer choice in this context, appeals to the volenti principle do make sense. So as long as people are able to freely and knowingly decide on what they consume there is nothing wrong in selling unhealthy foods.

This does not mean we cannot say anything about the moral impermissibility of promoting and selling unhealthy food products to consumers. The sales and marketing of unhealthy 
products would be harmful and thus morally wrong as a matter of non-maleficence if the volenti principle is not met - which is the case if there is insufficient room for autonomous decision-making. In the next subsection we explore in what ways consumer decision making can be unduly influenced in the sales of unhealthy products.

\section{Undue Corporate Influence on Autonomy}

Apart from the duty not to inflict harm, the notion of respecting autonomy is central to our more basic understandings of morality. As Beauchamp \& Childress state "to respect autonomous agents is to acknowledge their right to hold views, to make choices and to take action based on their personal values and beliefs"'(Beauchamp and Childress 2009, p. 103). It involves "the ability to deliberate, judge, choose and act upon different possible courses of action in both the private and public realm" (Held 2006, p. 263). This means that infringement of autonomy can take place both in the private realm (for instance in the market) as well as in the public realm (for instance in politics).

In business ethics the idea of respect for autonomy is often rephrased under the header of respect for consumer sovereignty ${ }^{3}$. This closely connects to one of the dominant assumptions in (classic) economics, namely that consumers are rational, autonomous actors that can make their own voluntary decisions. Corporations have to refrain from engaging in behaviour that would violate the autonomy of the consumers (Ebejer and Morden 1988; Hasnas 2009; Sher 2011). In regular market activities this principle is connected to the idea of honest dealing, meaning that transactions are only permissible as long as both parties knowingly and voluntarily consent to a deal (so indeed the idea of respect for autonomy, and the conditions of the volenti principle do coincide). In practice this means that when engaging with consumers firms should - at the very least - disclose all relevant information about a product in order to allow for the other party to make a well-informed decision. In addition, they should also refrain from unduly intervening in the decision-making process of the consumer (Ebejer and Morden 1988; Hasnas 2009).

If firms want to engage in morally acceptable behaviour, this means that they have to respect the autonomy of persons. The question of course is what kind of corporate behaviour can be seen as violating autonomy in these senses? Respect for autonomy not only entails that people have to be free to make their choice, it also implies that people have to be provided with information and reasons to make their choices. In our societal interactions we often do not merely provide information, it also entails persuading and influencing people. Providing people with information and communicating this to them in a fair fashion enables them to make their autonomous decisions. To illustrate this: we generally consider it laudable when a company informs a customer about the properties and potential value of a product or when the local government warns cyclists about dangerous crossings (cf. Sunstein 2016). Providing such information allows the individual to make a proper decision.

Still in reality this process of decision making is not always respected. Although straightforward coercion would will hardly ever happen in normal market contexts, other forms of

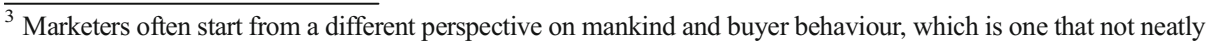
fits with the perspective of the homo economicus. For instance Freudian motivation theory or Veblenian theory assert that people are also motivated by subconscious desires (freedom, sex) or by the need to conform to larger cultural group norms (Mason 1984; Pincus 2004). We assert that while such considerations feed into the decision making process of people and affect the way consumers make decisions, people should be able to - at least partly - reflect on these desires and needs, weighing them in their decision to engage in specific behaviour (Crisp 1987).
} 
infringement on autonomy do occur often enough. People are deceived, lied to, kept in the dark and manipulated. We briefly discuss these ways of influencing people, point out why they are problematic and illustrate this with examples from the food industry.

\section{Deception, Lying and Keeping in the Dark}

One way in which autonomous decision-making processes can be hampered is by intentionally controlling people's information circumstances, leading to the creation of false or incomplete beliefs (Carsons 2009). Following Carsons we make the distinction between lying, deception, and keeping in the dark, as different ways in which informational circumstances can be impaired.

Lying can be understood as the act of making statements which one does not belief to be true (or rather, one beliefs to be false) with the intention of causing others to have false beliefs (Carsons 2009). This does take place in the food industry when firms make unsubstantiated claims about the nutritional value, health impact, or composition of their products. For instance the Dutch supermarket Jumbo advertised its 'honest cornbread', however - unlike the name suggested - the bread was not made of corn flour, but of regular wheat (Foodwatch 2017).

Deception is more subtle, but has the similar aim of causing another person to have false beliefs. A company deceives a consumer when it intentionally causes the consumer to believe something, while this something is false and the company also believes this to be false (cf. Carsons 2009). Deception can take many forms and shapes. In the food industry we see packaging and marketing that suggests that a product is healthy or contains a large portion of healthy ingredients, while this is not the case. For instance Sourcy's Raspberry Pomegranate Vitamin Water, contains no raspberry or pomegranate, but does consist of substantial amount of sugar. The fruit and vitamins are at the front of the pack, while the nutritional value is in very small cryptic text at the back of the bottle (Consumentenbond 2017). By communicating these products in such a way people are tricked into believing that they are healthy, fruity etc.

Keeping in the dark can be seen as a special way of with-holding relevant information for how we see and evaluate products ${ }^{4}$. Rather than actively lying or deceiving someone, a person can also refrain from telling the truth (cf. Carsons 2009). An example of this is how the American Sugar Research Foundation (SRF) operated in the 1960s and 1970s. At that time the general public was unaware of the dietary causes of coronary heart diseases, and the impact sugar consumption could have on health. While research in the early 1950s already revealed this connection, the SRF purposefully prevented this research from reaching the public, leading a majority of people to continue to have incorrect beliefs about the negative health effects of sugar (Kearns et al. 2016, 2018).

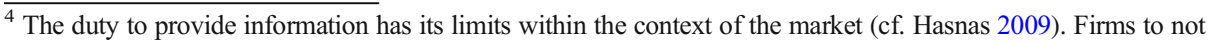
have to provide information on the exact production costs, but they have the responsibility to provide all relevant product information, for instance information that is not publicly available such as information on the nutritional make-up of a product or the negative effects this has on health. In order to engage in honest dealing firms should aim to make sure this information reaches the consumer. In interfirm interaction on the other hand withholding information can be permissible, or even necessary as it can be crucial for the survival firms to gain or maintain a competitive advantage. The duty to provide information seems to shift depending on whether one is dealing with consumers or other firms. This creates are paradox as firms on the one hand have to provide information, while at the same time have to keep it to themselves in order to survive in the market. For a more elaborate discussion on this information paradox see Blok (2018).
} 


\section{Manipulation}

While lying, deception and keeping in the dark are often seen as forms of manipulation, we propose that it can also be seen as covert interference with people's decision making processes. Manipulation changes people's behaviour, by sidestepping the normal process of persuasion and is in an underhand fashion changing the way people see their options (Groen-Reijman 2018).

Drawing on the work of Sunstein (2016) and Barnhill (2016) we find two ways in which such manipulation can be understood, namely as subversion of people's reflective deliberative capacities and as subversion of people's proper nondeliberative responses. Sunstein understands manipulation as actions that "do not sufficiently engage or appeal to their [people's] capacity for reflection and deliberation" (Sunstein 2016, p. 216). In the context of the market subliminal and subaudible advertising might be seen as a straight-forward examples of manipulation, while other practices such as redesigning a website in such a way that people become more inclined to buy the more expensive product could be seen a borderline cases. For Sunstein this type of influence is problematic as choosers did not have the fair opportunity to make a decision of their own, due to the interference of a (hidden) manipulator. Autonomy is infringed upon at the moment the manipulator is leading a person to make a choice without sufficiently weighing - on the chooser's own terms - the benefits and costs of a particular decision. People are not being treated with respect at the moment that their deliberative capacities are subverted (Sunstein 2016).

However, there are many choices and decisions people make that do not necessarily involve rational deliberation and reflection. Often our responses and behaviours in the world are not the product of our deliberative capacities, but occur emotionally and viscerally. For example, I feel attracted to my partner, I appreciate a pop song on the radio, and I enjoy the smell of freshly baked bread. None of these things are rational decisions, they come to me and I like them. These are what Barnhill calls proper nondeliberative responses. These responses should not be necessarily be understood as manipulative, for a person can reflect on them (Barnhill 2016).

In the case of advertising and sales we might argue that deliberative reflection and nondeliberative responses go hand-in-hand: we form proper non-deliberative responses (I enjoy the smell freshly baked croissants), we gather information (I read the price and nutritional value of a product) and on the basis of the our non-deliberative responses and the provided reasons and facts we engage in internal deliberation and reflection and come to a decision (I decide not to buy the delicious smelling croissant for I want to lose weight). Arguably, it would be impossible for us to navigate the world without relying on non-deliberative responses. Moreover, triggering these non-deliberative responses is of course a major and well-accepted element of common marketing strategies aiming to influence consumer choice.

Yet, these nondeliberative responses might also be flawed or improper due to undue influence of other actors. This can for instance happen by drawing spurious relations between products and desirable things. The tobacco industry marketed the cigarette as the torch of freedom, appealing to a subconscious desire to be free. While it is consistent with Freudian motivation theory to appeal to these elements, it does create a spurious relation, as smoking in no way strengthens one's freedom. That same thing happens when Coca-Cola in its commercials tries to make a connection between drinking Coca-Cola, happiness, and healthy beautiful people. As a result many people will first associate Coca-Cola with concepts as happy, healthy, beautiful, rather than view it as the sugary, energizing drink that it really is. This in turn impacts the human affect heuristic. Advertisements or campaigns can create positive emotional responses to products, which pre-empt a careful rational decision making process. Playing on 
the affect heuristic leads people to make snap-decisions, due to their association with desires like happiness or freedom, rather than making a well thought-through choice (Barnhill 2016).

On this basis of the above considerations we argue that actions are manipulative when: 1) an actor intentionally thwarts a person's rational deliberative capacities, and this person did not have sufficient opportunity to make a decision of his own due to this underhand interference of another actor; and 2) an actor intentionally triggers improper non-deliberative responses in a person that feed into his decision making process. Intentionally and covertly steering a consumer's practical reasoning and practical engagement with the world can be seen as problematic, for by (partly) taking over the decision making process, the manipulator is treating this person as both a 'tool and a fool' (Wilkinson 2013). In extreme cases this involves exercising power over that person - steering his life in a particular direction, rather than letting him determine his own desired path, infringing upon both autonomy and human dignity (Barnhill 2016; Groen-Reijman 2018; Sunstein 2016).

Many marketing techniques involve at least some manipulation or deception - and most consumers will be aware of that. To assume that the principle of respect for autonomy must be upheld in the market as strict as it upheld in for instance medical ethics, is rather implausible. Yet we have not only invoked respect for autonomy as a self-standing principle, but it is also linked to the principle of non-maleficence via the volenti principle. In the next section we argue that corporate actions that are in tension with both principles simultaneously can indeed be considered morally impermissible. We illustrate how these moral tensions are present in the sales and marketing of unhealthy foods and beverages.

\section{Towards Conditions for Judging the Moral Permissibility of Selling and Marketing Foods and Beverages}

In the above section we established that selling unhealthy food and beverage products does not have to be a problem, as long as the people have made a conscious and coercion-free decision to be exposed to the health risks. Yet, current research in health psychology and food sciences reveal that autonomous decision-making is under pressure. Our food choices and consumption behaviour are heavily influenced by product composition, the retail and eating environment as well as particular ways of product communication (Currie et al. 2009; Dobson and Gerstner 2010; Elliott 2015; Young and Nestle 2002). These persuasive practices are not necessarily problematic in a market context, although they can be considered to be in a moral grey zone. When you enter a shop or walk across the market place on a Saturday afternoon you will likely know that entrepreneurs will try to persuade you by arguments, tap into certain biological or social desires, influence you through sounds and images, all to ultimately invite you to buy their product or make use of their services. Influence and persuasion are part and parcel of market practice, and the vast majority of people are well aware of this (Beauchamp et al. 1984; Nairn and Fine 2008; Sunstein 2016).

Sunstein (2016) points out that manipulations are a pervasive feature of human life - they happens in our daily personal interactions, in the market, and in politics. Some are egregious such as subliminal messaging, questionable like scaring people using pictures, while others are mild - playing on loss aversion, changing tone of voice or using facial expressions. Yet all aim to steer people to make certain decisions. While these practices can partially infringe upon autonomy and human dignity, some of them are so engrained in our societal interactions - and 
this is certainly so in the market place - that it is difficult to argue that that all manipulative instances are inherently morally problematic (Sunstein 2016).

Still, this does not mean that there are no limits to the kind of influence that food firms are allowed to exercise on their (potential) customers. Even though (mild) manipulation is always present in the marketplace, we hold it to be unacceptable when it steers people towards unhealthy choices, for in that case both the principle of non-maleficence and that of respect for autonomy are violated. More specifically: in such cases companies cannot rebut the charge of harmful activity by appealing to the volenti principle. Below we explore under what conditions selling unhealthy foods is morally impermissible.

\section{Expectation of Being Manipulated}

One of the elements relevant in assessing the moral wrongness of manipulation in market contexts is the extent to which a consumer can reasonably expect to be manipulated. Taking this expectation seriously, we have reason to consider manipulative or slightly deceptive influences to be wrong when they happen in contexts where consumers do not expect them to occur. Consider for example the following: my local baker is leaving his oven on all day not because this is necessary, but because he knows that the smell of fresh products entices consumers to buy his products. Now, suppose the baker also installs little emitters in the local park next to the store that recreate the smell of fresh pastries, with the intention to seduce people to visit the store and buy pastries. While there is nothing inherently wrong with 'using' the smell of the oven to promote sales where I can expect it, to do so in the park would be an instance of wrongful manipulation. In the park I'm not expecting to be influenced by covert commercial interventions or cues. In a similar vein, publishing sugar industry sponsored articles on the importance of eating sugar in a newspaper section that looks like the regular science section, can also be considered manipulative or deceptive (see Royal Cosun 2017).

Consumers can furthermore reasonably expect to be influenced by the taste and look of a product. Yet, they will be less aware of specific cues in product formulation or product design, such as size relabelling. Keeping the consumer unaware of the fact that she is steered towards particular choices is morally problematic, and especially so if this stimulates unhealthy choices. In short: marketing strategies and product designs that are manipulative or otherwise undermine autonomous choice are morally wrong if used in contexts where a reasonable person would not expect them to occur.

\section{The Degree of Manipulation}

A second factor of moral (im)permissibility is the degree of manipulation. Minor manipulations are inevitable, but at some point they become morally wrong. In general one can argue that practices that subvert people's reflective capacities are more problematic than subversions of proper nondeliberative responses. Subliminal advertisements or some strategic product placements are likely to disable rational reflection and autonomous decision making. Improper nondeliberative responses on the other hand do not necessarily infringe upon autonomy. Creating spurious associations between a product and very attractive features, or manufacturing pleasant experiences are common marketing techniques that can effectively steer choice but reasonable people can still reflect on what is happening. Even though I might improperly associate Coca-Cola with world peace, or desire a product because there are attractive young people in the commercial, I can still assess these inputs next to the product information (facts), 
or taste (proper inputs) and make my own choices. Yet the more a practice undermines our reflective capacities, the more it is to be considered morally wrong.

We started from the assumption that ordinary morality - notably the principles of nonmaleficence and respect for autonomy - imposes restrictions on what can count as morally permissible corporate behaviour in the food industry. Due to the specific nature of the market context, such restrictions will be most obvious where the principles work in tandem, that is, where there is no ground for business to justify the sale of potentially harmful products by appeal to the volenti principle (i.e. arguing that consumers voluntary choose the products they buy). Unsafe products should not be marketed at all, which is (generally) governed by food law. In the case of unhealthy foods we have argued that it is morally impermissible to use manipulative strategies in contexts where consumers will not expect them at all, or where the strategies subvert reflective capacities to a high degree.

\section{A Special Case: Marketing Unhealthy Food and Beverages to Children}

Marketing to children is common practice in the food and beverage industry. From colourful food and packaging designs to advertisements featuring fun fictional characters and gamification, the range of marketing techniques is diverse and multi-faceted. And, it works: not only do advertisements and branding successfully influence children's beliefs and preferences about food and drinks, they also successfully affect parental purchasing (Cairns et al. 2013; Henry and Borzekowski 2011). Several scholars have highlighted these practices as irresponsible. What is held to be most problematic is the fact that food marketing aimed at children frequently promotes products that have a low nutritional value and are high in salt, sugar and fat. Over the past fifteen years the promotion of unhealthy products has rapidly increased compared to the promotion of healthy products (Dixon et al. 2017). Marketers tend to acknowledge that these practices are criticized for these effects, but in practice they show little willingness to refrain from engaging in child marketing (Adams 2007; Bergadaà 2007). Yet, the principles of ordinary morality give little reason to hold these practices to be morally permissible.

We established in the previous section that (mild) manipulation of consumers can only take place when they are aware of the fact that they might be steered towards a particular direction or manipulated into making specific choices. Bearing this in mind, marketing to children provides a curious case. It is generally assumed that while children from a young age on are able to engage in goal-directed behaviour and have specific preferences, they only gradually develop the competence and capacities for reflective decision making (Matthews and Mullin 2015). As such children do not have the capacity to identify, expect or reflect upon manipulation in sales and marketing.

While this limited autonomy of children is clearly recognized in legal and medical debates (cf. Beauchamp and Childress 2009), these considerations do not firmly hold sway in contemporary marketing practices. Marketing to children by now has a long tradition, not only in the sales of child specific products (toys, games) but also in the sales of food and beverage products. From a purely economic perspective it makes sense for firms to market to children: children can both be current customers as well as potential future consumers. However, taking the notion of consumer sovereignty seriously means acknowledging that children do not yet qualify as autonomous decision makers, as they do not have the reflective capacities to deal with all the tempting offers market players provide them with. 
Children are not yet able to (fully) discern and understand the consciously mediated persuasive information in marketing, let alone by able to identify the persuasive intent behind more covert marketing practices such as product placement in blogs and movies or gamification (this is already hard for many adult consumers) (Nairn and Fine 2008; Rozendaal et al. 2011). As a result they are easily being steered through the non-reflective behavioural responses triggered by corporate actors. It is for this reason that marketing of unhealthy products to (young) children can be seen as immoral and irresponsible. Not, for that matter, because their autonomy is not respected - after all it is questionable what it means to respect a child's autonomy if it is not considered sufficiently capable to make autonomous decisions at all. Yet for that reason, the volenti principle is not applicable either. Marketing unhealthy products can thus be considered as a case of harm that cannot be neutralised by appeal to the volenti principle.

There are two clear counterarguments to our objection to marketing to children. The first holds that while children are not yet autonomous, marketing can enable children to become full-fledged autonomous consumers. For instance Bergadaà points out that negative effects of marketing should not be tackled by "banning advertising targeted at young children. The ultimate aim is to ensure that our youth become enlightened consumers [...] it is the practice of consumerism that exposes children to the necessary socialization process for them to develop into aware adults." (Bergadaà 2007, p. 1). This implies that only by being confronted by child marketing children can learn how to become responsible consumers. However, this argument is flawed. While there might be reasons to argue that children living in a capitalist economic system should learn how to become critical consumers when they are adults, it seems questionable that in order to learn this, child marketing is important or necessary. Especially in the case of food and beverages there comes a moment that children simply are confronted with marketing of general food products. Marketing is so permeated in contemporary business practice, that we actually do not need child-focussed food products in order for them to learn about marketing practices. Simply by visiting a store, walking to school or by surfing online they are very likely to encounter Coca-Cola's Happiness campaign or Mondelēz's new Oreo advertisement. Even when one would hold that youth should learn to become sovereign consumers, they can do this through the encounters they will have with marketing of regular food and beverage products.

A second argument that could be made is that in most households children are not the primary shoppers. It are the parents who ultimately decide whether certain products are bought or not - and they will normally be capable to resist the slightly manipulative forms of child marketing. This is only partially true. Older children and teenagers will frequently buy their own lunches at school. Here they are being influenced by specific marketing, despite them not being sufficiently autonomous decision makers (cf. Nestle 2015). Yet even where parents make the decisions, child marketing is still problematic due to the nag-effect or so called pester-power. Children tend to start ask parents for the products that have been marketed to them, thereby pushing their parents to buy these specific products for them (Dixon et al. 2017; Henry and Borzekowski 2011). Such marketing techniques are not so much a problem because they would disrespect the autonomy of children or parents, but one can argue that deliberately marketing products towards children to make them influence their parents, involves using the children just as a means for corporate ends, which is a failure to respect the dignity of children. The notion of human dignity is a fundamental presupposition that precedes our consideration of respect for autonomy. It is generally assumed that human beings - adults and children have moral status and as such deserve to be treated with respect, and are to be treated as end in 
themselves and not merely as means (cf. Düwell 2011; Warren 1997). The practice of marketing unhealthy food to children violates this rule, as children are used as a tool to push parents to consume. Rather, parents should have a space in which they can educate their children to let them learn how to become autonomous actors, and this space should not interfered with for commercial reasons (cf. Paine et al. 1984).

Taking the above into account we argue that marketing unhealthy food to children and teenagers is problematic for both reasons of harm and dignity. As children do not have sufficient capacity for reflecting upon marketing, marketing unhealthy products to them subjects them health harms and risks they could not perceive, expect or consent to. Furthermore, steering them to either consume or pushing to their parents to consume fails respect their dignity. For those reasons we argue that marketing of unhealthy food and beverages to children and youth is immoral and irresponsible.

\section{Irresponsible Sales and Marketing of Unhealthy Food}

At the start of this article we set out to find under what conditions the sales and marketing of unhealthy food products can be seen as irresponsible. Following our analysis in the previous sections we can identify three conditions that determine whether marketing and sales of unhealthy food products are morally wrong:

1. the degree to which consumers are expecting to be manipulated;

2. the degree of manipulativeness of a product, design or marketing technique;

3. the degree to which a food or beverage product is harmful to health.

The first two conditions flow from our discussions of autonomy and the volenti principle, while the third is directly based on non-maleficence. Just like the first two conditions, the third can differ in degree: when you are unduly steered towards consuming a single ice cone, this would be less problematic than when you are manipulated into eating a 20,000 cal burger at the Heart Attack Grill ${ }^{5}$.

Despite all three conditions being on a sliding scale there are specific thresholds that should be met. Sales and marketing of harmful food products cannot take place, when: 1) it is aimed at actors who lack the capacity for reflection; 2) actions are highly manipulative; and 3) when products are legally deemed unsafe. This implies that the marketing of unhealthy food to children is a clear moral wrong, while marketing unhealthy products to adults might be permissible as long as the product is not unsafe, actions are not highly manipulative and consumers are made aware of the possibility of manipulation ${ }^{6}$.

This has clear and arguably far reaching implications for corporate practice. If food firms want to adhere to these minimal moral standards and engage in responsible behaviour, various

\footnotetext{
${ }^{5}$ What exactly counts as more or less unhealthy products and ingredients is not something we as philosophers aim to discuss in this paper. This is something that should be assessed by food scientists (Lobstein and Davies 2009).

${ }^{6}$ Whether it permissible or even laudable to nudge children and adults towards a healthy choice remains a topic of discussion. Following Sunstein (2016) we hold that such manipulation might be permissible on the grounds of welfare, but this requires further elaboration which goes beyond the scope of this article. For a more elaborate discussion see Bovens (2009), Conly (2012), Grüne-Yanoff (2012) and Hausman and Welch (2010).
} 
(radical) changes should be made to current business practice. In the next section we conclude the article and briefly discuss the practical implications of our findings.

\section{Discussion and Conclusion}

Adhering to the principles of ordinary morality theoretically broadens our notion of corporate (ir)responsibility in the food and beverage industry and it has clear implications for corporate practice. Living up the principles of respect for consumer autonomy and non-maleficence necessitates change in how firms operate within the market as well as in society at large.

\section{Towards Responsible Behaviour in the Food Market}

With regard to interaction within the market our findings in the first place have serious consequences for how these firms are to deal with children and teens. When firms market to children they use them as a tool for corporate gain, rather than as an end in themselves. The fact that many food products that are marketed to children are unhealthy food products, makes that the principle of non-maleficence is also infringed upon.

In order to act responsibly companies should refrain from marketing unhealthy food products to children below the age of 12 . This means that current practices such as promotion of products through character-branding, advergaming, commercials during TV-programs for children should be off the table. This by extension also implies that companies should rethink setting out marketing campaigns for their unhealthy products for adults from public spaces or institutions where there are a lot of children. Day cares, primary schools and sport associations would be credible candidates where such marketing would be off limits.

Secondly, it also requires firms to be sensible in marketing to teenagers. As their capacity for decision-making is more developed, the objection on grounds of autonomy is not as straight-forward as is the case with marketing to young children. Nevertheless, the fact these groups are still less able to engage in critical reflection, firms should clearly weigh what the negative impact of selling specific product to teenagers might be. It could for instance mean that firms still decide not to market or even sell certain products to adolescents. A practical example of this would be the decision of supermarkets to stop selling energy drinks to teenagers, because of the negative health effects (Kindelan 2018; Pieters 2018).

Our findings also impact how unhealthy food products are to be sold and marketed to adults. We have shown that impairing the information circumstances is morally dubious and that manipulation is only permissible under specific conditions. This provides the basis for several recommendations for corporate practice.

First and foremost firms should refrain from making health claims that are false. One cannot claim or suggest a product has certain healthy properties while this is not the case, like for instance Kellogg's did when claiming that their Rice Krispies were enhancing the immune system (Young 2010). In addition, firms can no longer keep people in the dark about what is in their products. They ought to make clear what the consequences of continued consumption can be when such knowledge is not publicly available.

Second, firms have to closely monitor whether an advertisement or product design might be deceptive. They should refrain from providing information in such a way that it is likely to cause faulty beliefs about the product. This for instance holds for products labels or 
commercials that suggest that a particular kind of ingredient is the main component (e.g. fruit, wholegrains etc.) while this is only a fraction of the entire product. So rather than putting a strawberry on the packaging when the product itself contains only $1 \%$ strawberry, it would be more truthful to add the line 'with strawberry flavour', doing more justice to actual content of the product - and reducing the odds of the consumer construing false beliefs.

While the above two elements are also clear candidates for governmental regulation, our final recommendation focusses directly on the firm, as we hold that in marketing to adults firms ought to operate in a prudent manner. Given that not all adult consumers are alike and equally capable of the assessing corporate manipulation, the most responsible thing to do would be to resist from engaging in manipulative behaviour in the first place. This especially holds when there are also other actions available that trigger the consumer's deliberative capacities and/or his proper nondeliberative responses. Should firms decide to engage in manipulation they should at the very least stay clear of highly manipulative tactics and make the consumer aware of the fact that they can be steered towards certain consumption patterns, both through the product, as well as by the consumption environment.

\section{Rethinking the Food industry's Involvement in Politics and Scientific Research}

Having addressed several issues in the market, important questions still remain on the (im)permissibility of activities of food firms that take place outside the sphere of the market. The food industry is often scrutinized for its impact on politics and scientific research, such as lobbying against public health regulation or disputing scientific consensus on the impact of unhealthy food (Bateman-House et al. 2017; Bødker et al. 2015; Kurzer and Cooper 2013; Oreskes and Conway 2010; Tselengidis and Östergren 2019).

Whether these activities are irresponsible are up for debate, as there is no consensus on the role corporations allowed to play in politics or in the pursuit of science (cf. Claassen and Gerbrandy 2018; Hussain and Moriarty 2018; Wettstein and Baur 2016; Tempels, Blok, and Verweij 2017). If we want a full and inclusive answer to the question what kind of behaviour of food firms in regard to public health is morally (un)acceptable, the food industry's impact on politics and scientific research should be assessed.

The notion of ordinary morality could well be a relevant starting point for such a reflection. If firms have the responsibility to respect people's autonomy both in their capacity as consumer, as well as in their capacity as citizens, this means that interfering with processes that enable people to deliberate and determine the collective ends of their society could be seen as violating citizen autonomy (cf. Groen-Reijman 2018; Held 2006). Hence when food corporations engage in behaviour that obscures facts about healthy consumption and even try to sow doubt about scientific consensus, this has a negative impact on the way in which citizens are able to deliberate about public policies, and in turn has detrimental effects for public health.

It goes beyond the scope of this particular article to discuss this in detail. Whether this behaviour is morally wrong and what the boundaries of political and social activities in the food industry could be, deserve to be addressed in future research.

\section{Concluding Remarks}

At the start of this article we set out to discuss what corporate irresponsibility in the food industry with regard to public health could entail, and we wondered specifically what could be the moral challenges in the sales and marketing of unhealthy products. We have argued that basic principles 
from ordinary morality, namely non-maleficence and respect for autonomy, provide moral guidance in how food firms ought to behave, both within the market as well as in society at large.

Our subsequent analysis revealed that there are clear moral minimums firms need to adhere to when producing, marketing and selling unhealthy products. The food and beverage industry is to refrain from marketing unhealthy food products to children and should reconsider marketing unhealthy products to adults. They are to take into account a) the manipulativeness of their marketing techniques, b) the degree to which consumers are able to identify possible manipulation and c) the possible negative impact (over)consumption of their product will have on public health. Not taking into account these basic conditions results in actions that are morally wrong and irresponsible. Our approach provides a basis for identifying what the food industry should no longer do in the sales of unhealthy products, shows what kind of behaviour would be more prudent, and points out that major changes in the industry are necessary.

Still our analysis is but a first step into getting a better understanding of the kind of responsibilities firms in the food and beverage industry could have, and how these could take shape in corporate practice. This article provides a generic normative analysis of (im)permissible corporate behaviour within a market context and as such our reflections are not without limitations. We were not able to take into account elements such as specific corporate concerns within different sectors of the food and beverage industry, cultural differences in food practices within different regions or countries, or the role firms and other societal actors play in the creation of an obesogenic environment (Barnhill et al. 2014; Chaput et al. 2011; Garst et al. 2017; Iivonen 2017). As such relevant research questions still remain and deserve to be taken up in future research. Only by also assessing concrete practices in the industry, analyzing perceptions of corporate responsibility within food firms and reflecting upon different food practices in different countries and cultures within a context of increasing obesogenic societies can we get a full grasp of what corporate responsibility for public health can entail.

This article makes a first contribution to furthering this understanding, as we make clear that only by adhering to ordinary morality can firms in the food and beverage industry move towards responsible behaviour, and contribute to a society in which freedom and well-being is respected. It provides a stepping stone for the development of a sophisticated and more encompassing research agenda on what corporate responsibility for public health in the context of the food industry could entail.

\section{Compliance with Ethical Standards}

Conflict of Interests Tjidde Tempels declares that he has no conflict of interest. Vincent Blok declares that he has no conflict of interest. Marcel Verweij is a member of CREAG, a group of experts that advises Unilever on ethical issues related to research involving human participants. He declares that he has no conflict of interests.

Ethical Approval This article does not contain any studies with human participants or animals performed by any of the authors.

Open Access This article is licensed under a Creative Commons Attribution 4.0 International License, which permits use, sharing, adaptation, distribution and reproduction in any medium or format, as long as you give appropriate credit to the original author(s) and the source, provide a link to the Creative Commons licence, and indicate if changes were made. The images or other third party material in this article are included in the article's Creative Commons licence, unless indicated otherwise in a credit line to the material. If material is not included in the article's Creative Commons licence and your intended use is not permitted by statutory regulation or exceeds the permitted use, you will need to obtain permission directly from the copyright holder. To view a copy of this licence, visit http://creativecommons.org/licenses/by/4.0/. 


\section{References}

Adams, C. 2007. Reframing the obesity debate: McDonald's role may surprise you. The Journal of Law, Medicine \& Ethics 35 (1): 154-157.

Afshin, A., P.J. Sur, K.A. Fay, L. Cornaby, G. Ferrara, J.S. Salama, et al. 2019. Health effects of dietary risks in 195 countries, 1990-2017: A systematic analysis for the global burden of disease study 2017. The Lancet 393 (10184): 1958-1972.

Barnhill, A. 2016. I'd like to teach the world to think: Commercial advertising and manipulation. Journal of Marketing Behavior 1 (3-4): 307-328.

Barnhill, A., K.F. King, N. Kass, and R. Faden. 2014. The value of unhealthy eating and the ethics of healthy eating policies. Kennedy Institute of Ethics Journal 24 (3): 187-217.

Bateman-House, A., R. Bayer, J. Colgrove, A.L. Fairchild, and C.E. McMahon. 2017. Free to consume? Antipaternalism and the politics of New York City's soda cap Saga. Public Health Ethics 11 (1): 45-53. https://doi.org/10.1093/phe/phw046.

Beauchamp, T.L., and J.F. Childress. 2009. Principles of biomedical ethics. Oxford: Oxford University Press.

Beauchamp, T.L., R.M. Hare, and B. Biederman. 1984. Manipulative advertising [with commentaries]. Business \& Professional Ethics Journal 3 (3/4): 1-30.

Bergadaà, M. 2007. Children and business: Pluralistic ethics of marketers. Society and Business Review 2 (1): 53-73.

Bødker, M., C. Pisinger, U. Toft, and T. Jørgensen. 2015. The rise and fall of the world's first fat tax. Health Policy 119 (6): 737-742.

Bovens, L. (2009). The ethics of nudge. In Preference change (pp. 207-219). Dordrecht: Springer.

Blok, V., Tempels, T., Pietersma, E., \& Jansen, L. (2017). Exploring Ethical Decision Making in Responsible Innovation: The case of innovations for health food. In Responsible Innovation 3 (Vol. 3). Dordrecht: Springer International Publishing.

Blok, V. (2018). Information asymmetries and the paradox of sustainable business models: Towards an integrated theory of sustainable entrepreneurship. In Sustainable Business Models. Dordrecht: Springer.

Brenkert, G.G. 2008. Marketing ethics. Malden: Blackwell Publishers.

Brink, D. (2016). Mill's moral and political philosophy. In E. N. Zalta (Ed.), The Stanford Encyclopedia of Philosophy (winter 2016). Retrieved from https://plato.stanford.edu/archives/win2016/entries/mill-moral-political/

Brockway, G. 1993. Limited paternalism and the salesperson: A reconsideration. Journal of Business Ethics 12 (4): 275-279. https://doi.org/10.1007/BF01666531.

Brownell, K.D., and K.E. Warner. 2009. The perils of ignoring history: Big tobacco played dirty and millions died. How similar is big food? The Milbank Quarterly 87 (1): 259-294. https://doi.org/10.1111/j.14680009.2009.00555.x.

Cairns, G., K. Angus, G. Hastings, and M. Caraher. 2013. Systematic reviews of the evidence on the nature, extent and effects of food marketing to children. A retrospective summary. Appetite 62: 209-215.

Carsons, T.L. 2009. Deception and information disclosure in business and professional ethics. In The Oxford handbook of business ethics, ed. G.G. Brenkert and T.L. Beauchamp. Oxford: Oxford University Press.

Chaput, J.-P., L. Klingenberg, A. Astrup, and A.M. Sjödin. 2011. Modern sedentary activities promote overconsumption of food in our current obesogenic environment. Obesity Reviews: An Official Journal of the International Association for the Study of Obesity 12 (5): e12-e20. https://doi.org/10.1111/j.1467-789X.2010.00772.x.

Claassen, R., and A. Gerbrandy. 2018. Doing good together: Competition law and the political legitimacy of Interfirm cooperation. Business Ethics Quarterly: 1-25.

Conly, Sarah. 2012. Against autonomy: Justifying coercive paternalism. Cambridge: Cambridge University Press.

Conly, S. 2013. Coercive paternalism in health care: Against freedom of choice. Public Health Ethics 6 (3): 241245. https://doi.org/10.1093/phe/pht025.

Consumentenbond. (2017). Sourcy Vitaminwater framboos granaatappel | Consument. Retrieved November 18, 2018, from https://www.consumentenbond.nl/acties/kletsplaatjes/sourcy-vitaminwater

Crisp, R. 1987. Persuasive advertising, autonomy, and the creation of desire. Journal of Business Ethics 6 (5): 413-418. https://doi.org/10.1007/BF00382898.

Crossley, D. 1999. Paternalism and corporate responsibility. Journal of Business Ethics 21 (4): 291-302. https://doi.org/10.1023/A:1005937807850.

Currie, J., DellaVigna, S., Moretti, E., \& Pathania, V. 2009. The effect of fast food restaurants on obesity and weight gain. National Bureau of Economic Research.

Dixon, H., P. Niven, M. Scully, and M. Wakefield. 2017. Food marketing with movie character toys: Effects on young children's preferences for unhealthy and healthier fast food meals. Appetite 117: 342-350.

Dobson, P.W., and E. Gerstner. 2010. For a few cents more: Why supersize unhealthy food? Marketing Science 29 (4): 770-778.

Dorfman, L., A. Cheyne, L.C. Friedman, A. Wadud, and M. Gottlieb. 2012. Soda and tobacco industry corporate social responsibility campaigns: How do they compare? PLoS Medicine 9 (6): e1001241. 
Düwell, M. 2011. Human dignity and human rights. In P. Kaufmann, H. Kuch, C. Neuhaeuser, \& E. Webster (Eds.), Humiliation, Degradation, Dehumanization: Human Dignity Violated (pp. 215-230). https://oi. org/10.1007/978-90-481-9661-6_15.

Ebejer, J.M., and M.J. Morden. 1988. Paternalism in the marketplace: Should a salesman be his buyer's keeper? Journal of Business Ethics 7 (5): 337-339. https://doi.org/10.1007/BF00382535.

Elliott, C. 2015. 'Big Food'and 'gamified'products: Promotion, packaging, and the promise of fun. Critical Public Health 25 (3): 348-360.

Epstein, R.A. 2004. What (not) to do about obesity: A moderate Aristotelian answer. Geo. LJ, 93, 1361.

Feinberg, J. 1989. The moral limits of the criminal law: Volume 3: Harm to self. USA: Oxford University Press.

Foodwatch. 2017. Wint Jumbo het Gouden Windei? Maïsbrood van tarwemeel. Stem nu! Retrieved November 18, 2018, from https:/www.foodwatch.org/nl/onze-campagnes/onderwerpen/misleidende-marketing/hetgouden-windei/nu-stemmen-gouden-windei-2017/jumbo-goudeerlijk-boerenmais/

Garst, J., Blok, V., Jansen, L., \& Omta, O. (2017). Responsibility versus Profit: The Motives of Food Firms for Healthy Product Innovation. Sustainability 9 (12), 2286.

Gert, B. 2004. Common morality: Deciding what to do. Oxford: Oxford University Press.

Gilmore, A.B., E. Savell, and J. Collin. 2011. Public health, corporations and the new responsibility deal: Promoting partnerships with vectors of disease? Journal of Public Health 33 (1): 2-4.

Groen-Reijman, E. 2018. Deliberative Political Campaigns: Democracy, Autonomy and Persuasion (University of Amsterdam). Retrieved from http://hdl.handle.net/11245.1/4f305207-9e4a-4559-b1c9-8a29fc127d31

Grüne-Yanoff, T. 2012. Old wine in new casks: Libertarian paternalism still violates liberal principles. Social Choice and Welfare 38 (4): 635-645.

Harris, J.L., J.L. Pomeranz, T. Lobstein, and K.D. Brownell. 2009. A crisis in the marketplace: How food marketing contributes to childhood obesity and what can be done. Annual Review of Public Health 30 (1): 211-225. https://doi.org/10.1146/annurev.publhealth.031308.100304.

Hasnas, J. 2009. The mirage of product safety. In The Oxford handbook of business ethics, ed. G.G. Brenkert and T.L. Beauchamp. Oxford: Oxford University Press.

Hastings, G. (2012). Why corporate power is a public health priority. BMJ 345: e5124.

Hausman, D.M., and B. Welch. 2010. Debate: To nudge or not to nudge. Journal of Political Philosophy 18 (1): $123-136$.

Heath, J. 2007. An adversarial ethic for business: Or when sun-Tzu met the stakeholder. Journal of Business Ethics 72 (4): 359-374.

Held, D. 2006. Models of democracy. Malden: Polity Press.

Henry, H.K., and D.L. Borzekowski. 2011. The nag factor: A mixed-methodology study in the US of young children's requests for advertised products. Journal of Children and Media 5 (3): 298-317.

Hsieh, N. 2017. The responsibilities and role of business in relation to society: Back to basics? Business Ethics Quarterly 27 (2): 293-314. https://doi.org/10.1017/beq.2017.8.

Hussain, W., and J. Moriarty. 2018. Accountable to whom? Rethinking the role of corporations in political CSR. Journal of Business Ethics 149 (3): 519-534. https://doi.org/10.1007/s10551-016-3027-8.

Iivonen, K. 2017. Defensive responses to strategic sustainability paradoxes: Have your coke and drink it too! Journal of Business Ethics: 1-19. https://doi.org/10.1007/s10551-017-3580-9.

Imamura, F., R. Micha, S. Khatibzadeh, S. Fahimi, P. Shi, J. Powles, et al. 2015. Dietary quality among men and women in 187 countries in 1990 and 2010: A systematic assessment. The Lancet Global Health 3 (3): e132-e142.

Katan, M.B. 2017. Wat is nu gezond? Fabels en feiten over voeding. 23rd ed. Amsterdam: Bert Bakker.

Kearns, C., L. Schmidt, and S. Glantz. 2016. Sugar industry and coronary heart disease research: A historical analysis of internal industry documents. JAMA Internal Medicine 176 (11): 1680-1685. https://doi. org/10.1001/jamainternmed.2016.5394.

Kearns, C., L. Schmidt, D. Apollonio, and S. Glantz. 2018. The sugar industry's influence on policy. Science 360 (6388): 501-501.

Kindelan, K. 2018. Some UK supermarkets to ban selling energy drinks to anyone under 16. Retrieved October 6, 2018, from ABC news website: https://abcnews.go.com/GMA/Wellness/uk-supermarkets-ban-sellingenergy-drinks-16/story?id=53528673

Kurzer, P., and A. Cooper. 2013. Biased or not? Organized interests and the case of EU food information labeling. Journal of European Public Policy 20 (5): 722-740. https://doi.org/10.1080 /13501763.2012.751703.

Leighton, P. 2016. Mass Salmonella poisoning by the Peanut Corporation of America: State-corporate crime involving food safety. Critical Criminology 24 (1): 75-91. https://doi.org/10.1007/s10612-015-9284-5.

Lichtenberg, J. 2010. Negative Duties, Positive Duties, and the "New Harms". Ethics 120 (3): 557-578. https://doi.org/10.1086/652294.

Lobstein, T., and S. Davies. 2009. Defining and labelling 'healthy' and 'unhealthy' food. Public Health Nutrition 12 (3): 331-340. https://doi.org/10.1017/S1368980008002541. 
Marks, JH. (2017) Caveat Partner: Sharing Responsibility for Health With the Food Industry. American Journal of Public Health 107 (3):360-361

Marler, B. 2018. Food "Crimes"-When to Prosecute and When to Not? Retrieved July 11, 2018, from Forbes website: https:/www.forbes.com/sites/billmarler/2015/07/18/food-crimes-when-to-prosecute-and-when-to-not/

Mason, R. 1984. Conspicuous consumption: A literature review. European Journal of Marketing 18 (3): 26-39. https://doi.org/10.1108/EUM0000000004779.

Matthews, G., \& Mullin, A. 2015. The philosophy of childhood. In E. N. Zalta (Ed.), The Stanford Encyclopedia of Philosophy (Spring 2015). Retrieved from https://plato.stanford.edu/archives/spr2015/entries/childhood/

McKee, M., and D. Stuckler. 2018. Responding to the corporate and commercial determinants of health. American Journal of Public Health (0): e1-e4.

Micha, R., S. Khatibzadeh, P. Shi, K.G. Andrews, R.E. Engell, and D. Mozaffarian. 2015. Global, regional and national consumption of major food groups in 1990 and 2010: A systematic analysis including 266 countryspecific nutrition surveys worldwide. BMJ Open 5 (9): e008705.

Moss, M. 2013. Salt, sugar, fat: How the food giants hooked us. New York: Random House.

Nairn, A., and C. Fine. 2008. Who's messing with my mind? The implications of dual-process models for the ethics of advertising to children. International Journal of Advertising 27 (3): 447-470.

Nestle, M. 2013. Food politics: How the food industry influences nutrition and health. Vol. 3. Berkeley: University of California Press.

Nestle, M. 2015. Soda politics: Taking on big soda (and winning). Oxford: Oxford University Press.

Nestle, M. 2018. Unsavory truth: How food companies skew the science of what we eat. New York: Basic Books.

Norman, W. 2011. Business ethics as self-regulation: Why principles that ground regulations should be used to ground beyond-compliance norms as well. Journal of Business Ethics 102 (1): 43-57.

Oreskes, N., and E.M. Conway. 2010. Defeating the merchants of doubt. Nature 465 (7299): 686.

Paine, L.S., G.G. Brenkert, R. Weisskoff, and L.D. Kimmel. 1984. Children as consumers: An ethical evaluation of Children's television advertising [with commentaries]. Business \& Professional Ethics Journal 3 (3/4): 119-169.

Pieters, J. 2018. Aldi, Lidl to stop selling energy drinks to kids. Retrieved October 6, 2018, from NL times website: https://nltimes.nl/2018/07/03/aldi-lidl-stop-selling-energy-drinks-kids

Pincus, J. 2004. The consequences of unmet needs: The evolving role of motivation in consumer research. Journal of Consumer Behaviour 3 (4): 375-387. https://doi.org/10.1002/cb.149.

Royal Cosun. 2017 . SUIKER. NRC XTR. Retrieved from https://www.nrc.nl/advertentie/royal-cosun/

Rozendaal, E., M.A. Lapierre, E.A. van Reijmersdal, and M. Buijzen. 2011. Reconsidering advertising literacy as a defense against advertising effects. Media Psychology 14 (4): 333-354. https://doi.org/10.1080 $/ 15213269.2011 .620540$.

Schrempf, J. 2014. A social connection approach to corporate responsibility the case of the fast-food industry and obesity. Business \& Society 53 (2): 300-332. https://doi.org/10.1177/0007650312449577.

Sher, S. 2011. A framework for assessing immorally manipulative marketing tactics. Journal of Business Ethics 102 (1): 97-118.

Stuckler, D., and M. Nestle. 2012. Big food, food systems, and Global Health. PLoS Medicine 9 (6): e1001242. https://doi.org/10.1371/journal.pmed.1001242.

Stuckler, D., M. McKee, E. Shah, and B. Sanjay. 2012. Manufacturing epidemics: The role of global producers in increased consumption of unhealthy commodities including processed foods, alcohol, and tobacco. PLoS Medicine 9 (6). https://doi.org/10.1371/journal.pmed.1001235.

Sunstein, C.R. 2016. Fifty shades of manipulation. Journal of Marketing Behavior 1 (3-4): 213-244.

Swinburn, B.A., G. Sacks, K.D. Hall, K. McPherson, D.T. Finegood, M.L. Moodie, and S.L. Gortmaker. 2011. The global obesity pandemic: Shaped by global drivers and local environments. The Lancet 378 (9793): 804-814.

Tempels, T., Blok, V., \& Verweij, M. (2017). Understanding Political Responsibility in Corporate Citizenship: Towards a shared responsibility for the common good. Journal of Global Ethics 1 (13): 90-108. https://oi. org/10.1080/17449626.2017.1320577

Tempels, T., Verweij, M., \& Blok, V. (2017). Big Food's Ambivalence: Seeking Profit and Responsibility for Health. American Journal of Public Health 107 (3), 402-406. https://doi.org/10.2105/AJPH.2016.303601

Tselengidis, A., and P.-O. Östergren. 2019. Lobbying against sugar taxation in the European Union: Analysing the lobbying arguments and tactics of stakeholders in the food and drink industries. Scandinavian Journal of Public Health 47 (5): 565-575. https://doi.org/10.1177/1403494818787102.

Warren, M.A. 1997. Moral status: Obligations to persons and other living things. Wotton-under-Edge: Clarendon Press.

Wettstein, F., and D. Baur. 2016. "Why should we care about marriage equality?": Political advocacy as a part of corporate responsibility. Journal of Business Ethics 138 (2): 199-213. https://doi.org/10.1007/s10551-0152631-3. 
WHO. (2018). Obesity and overweight. Retrieved April 21, 2019, from Obesity and overweight website: https://www.who.int/news-room/fact-sheets/detail/obesity-and-overweight

Wilkinson, T.M. 2013. Nudging and Manipulation. Political Studies 61 (2): 341-355. https://doi.org/10.1111 j.1467-9248.2012.00974.x.

Yoon, S., and T.-H. Lam. 2013. The illusion of righteousness: Corporate social responsibility practices of the alcohol industry. BMC Public Health 13 (1): 630.

Young, L. R., \& Nestle, M. (2002). The contribution of expanding portion sizes to the US obesity epidemic. American Journal of Public Health 92 (2): 246-249.

Young, S. (2010, June 4). Kellogg settles Rice Krispies false ad case. Retrieved October 6, 2018, from http:/thechart.blogs.cnn.com/2010/06/04/kellogg-settles-rice-krispies-false-ad-case/

Publisher's Note Springer Nature remains neutral with regard to jurisdictional claims in published maps and institutional affiliations. 